\title{
Analysis of Passenger Car Emission Factors in RDE Tests
}

\author{
Jacek Pielecha1,a, Jerzy Merkisz¹ ${ }^{1}$, Jarosław Markowski ${ }^{1}$ and Remigiusz Jasiński1 \\ ${ }^{1}$ Poznan University of Technology, Institute of Combustion Engines and Transport, 60-965 Poznan, Poland
}

\begin{abstract}
The article presents a study on emission measurements in passenger cars in tests conducted under real traffic conditions - Real Driving Emissions using a Portable Emission Measurement System type of equipment. A special feature of the outlined RDE tests is that they were performed in Polish road conditions, and thus their parameters may differ from their counterparts adopted in most European Union countries. Based on the findings vehicle emission conformity factors were developed, characterized as the fractional increase (or decrease) of traffic emissions during the homologation test or under normal operation conditions in relation to the emission limit standards (for chosen emission class) of the vehicle. Conducted research and the calculated conformity factors allowed for the environmental impact assessment of the vehicles of various emission classes, while also allowing early actions to restrict the emissions of selected components in passenger vehicles. The methods and measures used can also be applied to other types of vehicles (e.g. heavy duty or off-road vehicles) or vehicles powered by other fuels.
\end{abstract}

\section{Introduction}

A fundamental factor leading to technology development in all branches of industry is the need to reduce its negative impact on natural environment. Transport is one of the most dynamically changing fields of economy, particularly due to the ever-changing exhaust emission levels. Increasing emphasis is put on the measurements of exhaust emissions, from combustion engines of machines and vehicles especially under actual operating conditions.

These measurements much better reflect the environmental situation than the tests only simulating actual conditions of operation used thus far or stationary tests. These measurements became possible due to a significant advancement in the area of measurement techniques in recent years. Passenger vehicles are subject to intermittent inspections at inspection stations, however the inspections are carried out for a limited (much lower than in real traffic) operating range of the engine. The assessment of the environmental performance of the vehicles may also be carried out on a chassis dynamometer. It is quite opposite for heavy-duty vehicles, in which case, in order to assess the in-service emissions, the engine must be removed from the vehicle for testing. Statistical research on a chassis dynamometer may sometimes be performed on vehicles of different applications, while the tests used in the methodology designed to assess the emissions are not at all different. The proposal for tests utilizing portable measurement systems is a universal solution as it can be used for vehicles of different applications in which the same engines were fitted.

The growing number of vehicles in the world and the resultant natural environment pollution leads to a growth in the emission related requirements. Current level of technology advancement in all the fields of industry including transport results in a growth of the requirements for the emission measurement devices. In order for these requirements to be fulfilled to comply with the ever-changing regulations a concentration of industry became necessary in this matter. The exhaust emission tests are a sophisticated process. Modern analyzers of the emissions require special laboratory conditions and the homologation procedures comprise tests on chassis and engine dynamometers that do not entirely reflect the emissions under real operating conditions. The latest results of on-road tests show that in relation to some exhaust components the emission is higher by several hundred percent for both the gaseous compounds and particulate matter. Hence, we can see a trend attempting at a formalization and enforcement of the on-road emission testing.

Recent research on pollutant emissions under real traffic conditions performed using mobile devices $[1,2]$ reflects the state of ecological vehicles very well. Most attention is paid to the possibility of using such research to calibrate engines [3], in such a way so as to limit emissions not only during the emission test [4], but also over the whole engine operating range $[5,6]$. Comparative laboratory testing conducted on chassis dynamometers [7] has revealed the compliance

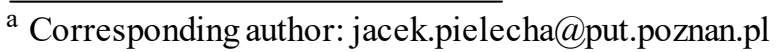


of vehicles with gasoline and Diesel engines with exhaust emissions standards, while testing carried out under real driving conditions has shown that vehicles with Diesel engines significantly exceed $\mathrm{NO}_{\mathrm{x}}$ emissions limits [8-10]. Attention is drawn to the importance of particulate exhaust emissions, mainly in the form of nanoparticles emitted from internal combustion engines (gasoline engines with direct fuel injection, as well as Diesels equipped with a particulate filter (DPF)) [11]. The results of such studies are currently not presented independently, but have been confirmed by publications which encompass investigations spanning several years [12] and comprehensive summaries of vehicles tested under real traffic conditions [13].

\section{Polish automotive market analysis}

The number of motor vehicles in Poland, particularly passenger vehicles (4/5 of total vehicles), has grown significantly in recent years. In 2015 there were 20.1 million passenger vehicles with the European (European Union) average of 9.3 million per country (Fig. 1) [14].

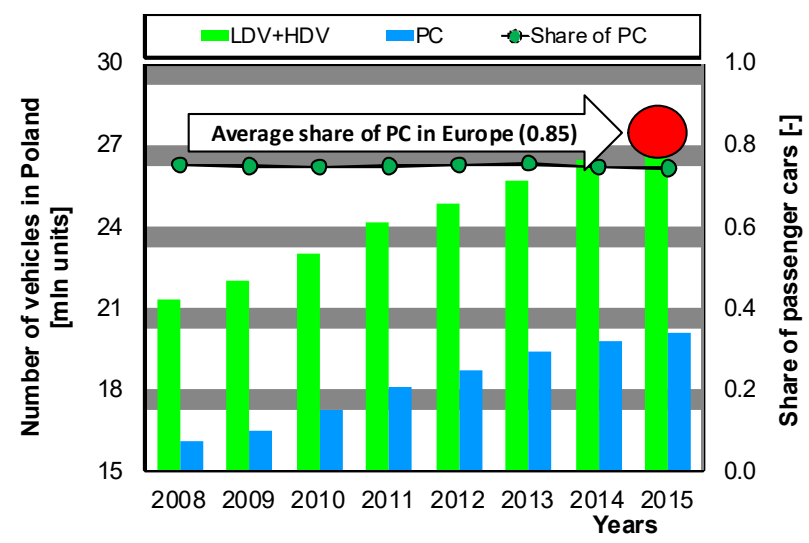

Figure 1. Motor vehicles in Poland [14, 15].

In Poland in 2015, 800 thousand vehicles were registered for the first time including 720 thousand passenger vehicles and 94 thousand heavy-duty trucks and road tractor units (Fig. 2). The increase in the vehicle fleet was mainly caused by private import. In 2013 there were 599 passenger vehicles per 1000 citizens (average for European countries amounts to 564).

Mass import of used vehicles adversely influences the age structure of the vehicles. Ever since the accession of Poland to the European Union, the imported vehicles are mostly older than 4 years of age (92\% in 2014), which is why the vehicle fleet in Poland is growing old. In 2014 there were $9.5 \%$ of 5 year old or younger vehicles $-0.7 \%$ less than in the previous year (Fig. 3 ) [14]. In 2003, prior to the accession of Poland to the European Union, when old vehicles import limitations applied there were over $18 \%$ of vehicles of 5 years old or younger. The share of vehicles from 6 to 15 years old in 2013 was 19.2\% (Euro 2 and Euro 3) and 16 -20 year old vehicles $-21.1 \%$ (Euro 1 ) and in both cases this share was over 4\% greater than in 2012 . There were approx. 7 times more vehicles exceeding 20 years of age in 2012 than vehicles of the age of up to 2 years (Fig. 4).
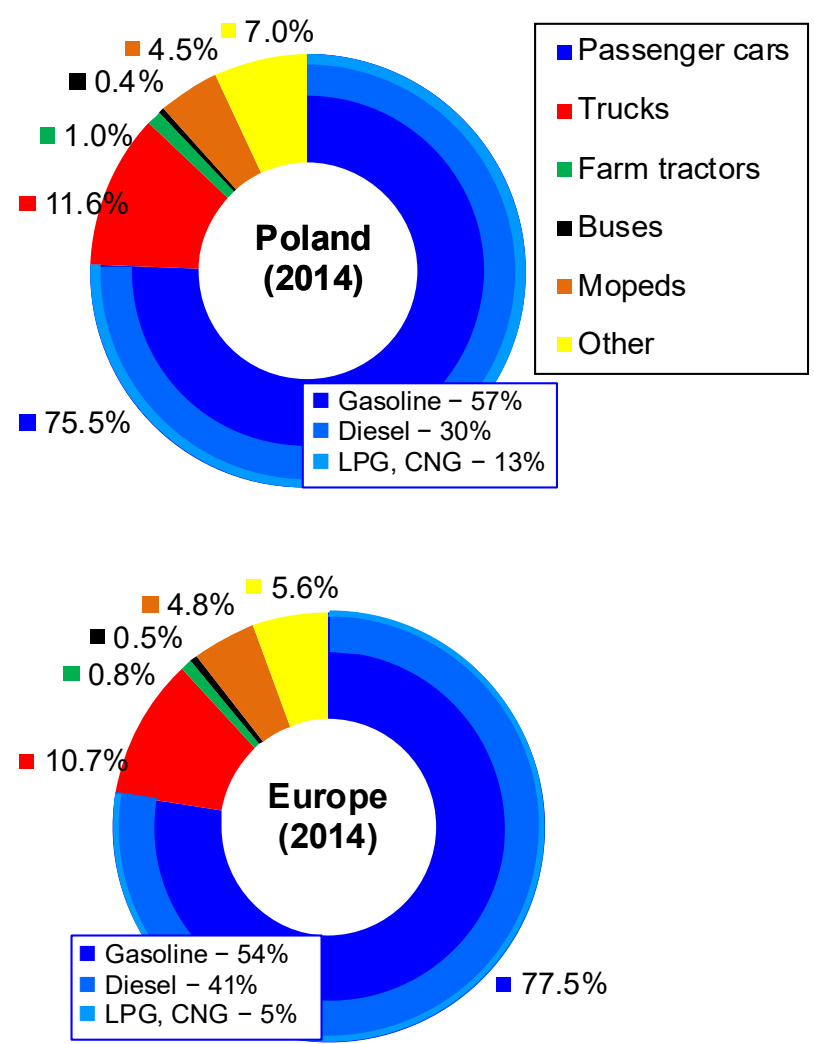

Figure 2. Vehicle structure in Poland and Europe in 2014 (based on $[14,15]$ ).

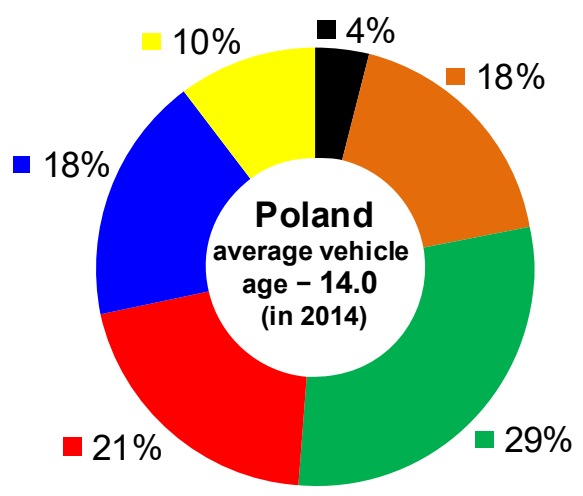

- Euro 5
Euro 4
- Euro 3
-Euro 2
- Euro 1
Euro 0

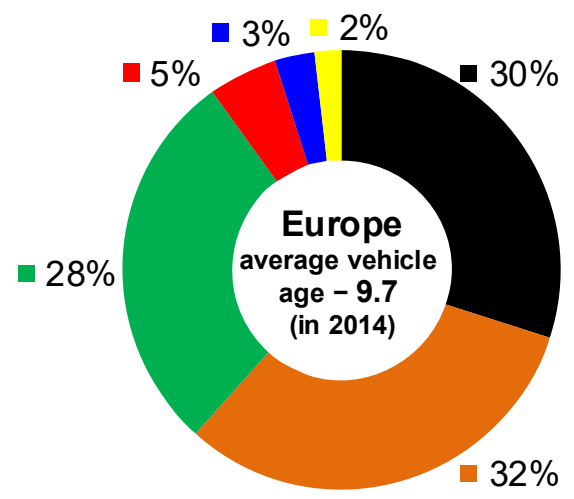

Figure 3. Emission categories of vehicles in Poland and Europe (based on $[14,15]$ ). 
In Europe the share of vehicles of up to 5 years constitutes approx. 30\% (Euro 5) and at the same time the share of vehicles in the range of 5-10 years (Euro 4) is not much higher. There are not many vehicles older than 10 years - approx. 37\% (Euro 3 - Euro 0). The consequence of maintaining an old vehicle fleet (more than half of the vehicles comply to the Euro 2 and Euro 3 exhaust emission standards) is borne not only by the vehicle owners but also the society. Old and deteriorated vehicles are less safe and their environmental performance is poor - they generate much more pollution than new vehicles.

\section{Research methodology}

\subsection{Real Driving Emissions}

A variety of conditions that have an impact on the level of emissions occur under real driving conditions. These variables cause results that are not identical to the results obtained during emission tests performed on a chassis test bench, where the conditions are fully repeatable. The relatively worse repeatability of the results obtained is primarily affected by:

- environmental conditions (variable temperature, pressure, humidity, wind rate, rain, snow, etc.),

- the quality of the road surface,

- traffic congestion,

- the driver's behavior: aggressive, neutral, eco-driving.

The authors propose the introduction of emission correction coefficients (as initially presented in a publication from 2009 [16]), being the multiple of the increase (or decrease) of emissions under real driving conditions in relation to the type approval test emissions results. Such coefficients $(C F-$ conformity factor) for regulated emissions are defined as follows:

$$
C F_{j}=\frac{E_{\mathrm{RDE}, j}}{E_{\mathrm{norm}, j}}
$$

where:

$j \quad$ - the harmful compound for which the conformity factor was specified,

$E_{\mathrm{RDE}, j}$ - road emission obtained under real driving conditions $([\mathrm{mg} / \mathrm{km}])$,

$\mathrm{E}_{\mathrm{norm}, j}$ - value of emission limit in the applicable emission standard ([mg/km]).

The conformity factor can usually be calculated as the value relating to the entire test, which is the ratio of emission of the pollutant in the road test performed under real driving conditions to the normative value. The conditions under which the road tests (Fig. 4) were carried out were characterized by the following properties (as defined in EU legislation on RDE testing):

- $33 \%$ of the total time performed under urban conditions, in which the vehicle's speed does not exceed $50 \mathrm{~km} / \mathrm{h}$ (with cold start),

- $33 \%$ of the total time performed under extra-urban driving, in which vehicle's speed is in the range 50-90 $\mathrm{km} / \mathrm{h}$,
- $33 \%$ of the total time performed in a highway driving in which the vehicle's speed is in the range $90-130 \mathrm{~km} / \mathrm{h}$ (not to exceed $140 \mathrm{~km} / \mathrm{h}$ ).

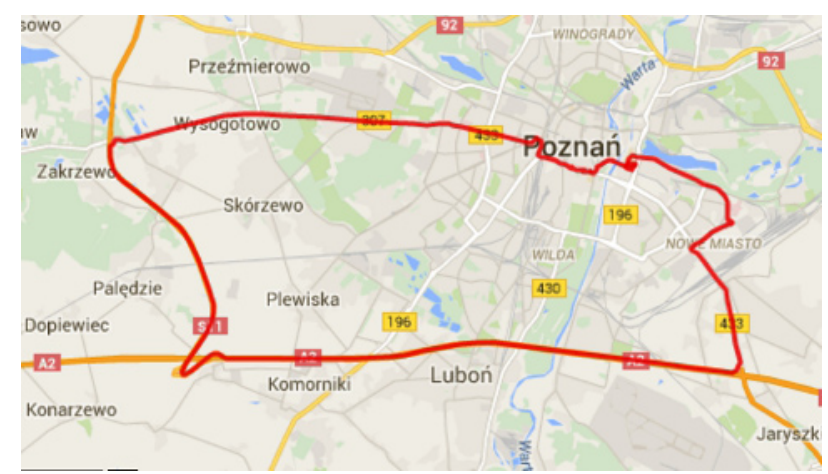

$\overline{\text { Figure }} \overline{4}$. The measuring route (Poznan).

\subsection{Tested vehicles}

The results of emission testing presented here are the fruit of a 9-year program connected with the study of cars under real traffic conditions. Tests were made on a group of over 150 cars with differing technical parameters (Fig. 5). The study involved vehicles powered by both Gasoline and Diesel engines of various displacements (from $0.7 \mathrm{~L}$ to $3.0 \mathrm{~L}$ ) and fitted with different emission aftertreatment systems. Data presented in this paper relate to road tests performed on different cars with various mileages using various fuel supply systems (various layouts for both gasoline and Diesel engines). The results are divided into categories by emission standard (Euro 4, Euro 5 and Euro 6), while results for vehicles fulfilling lower, earlier emission standards are not included. The road emissions results acquired were ranked from lowest to highest and only extreme values were presented (results obtained under conditions which did not fulfill the requirements relating to on-road testing described in later sections of this paper were rejected).

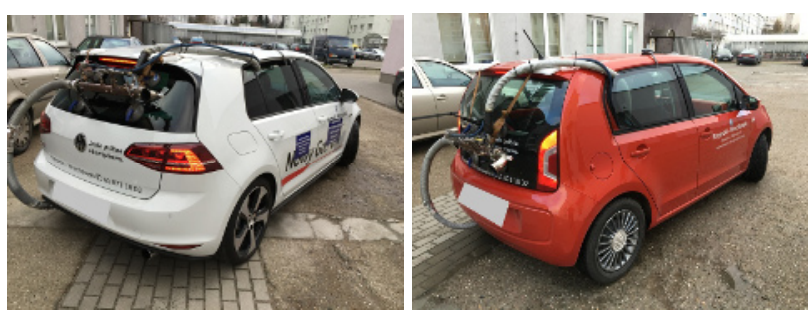

Figure 5. Vehicles used for tests (examples).

\subsection{Research apparatus}

The testing apparatus is presented in Fig. 6a. A portable Semtech DS analyser was used for the measurement of exhaust emissions from vehicles (Fig. 6b). It allowed measurements of carbon monoxide, carbon dioxide, hydrocarbons, non-methane hydrocarbons and nitrogen oxides exhaust emissions. A portable AVL M.O.V.E PM (Micro Soot Sensor) analyser was used to measure particle mass (Fig. 7a), while a PMP-compliant AVL condensation particle counter was used to measure particle number emissions (Fig. 7b). The emissions 
measurement equipment had a maximum mass of $116 \mathrm{~kg}$ (Gas PEMS - 25 kg; PM PEMS - 45 kg, PN Counter $25 \mathrm{~kg}$ ), together with an additional power supply (generator) $-21 \mathrm{~kg}$. a)

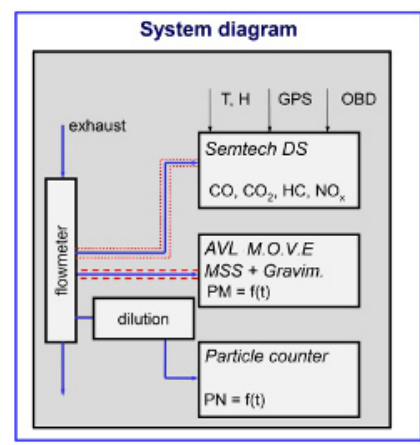

b)

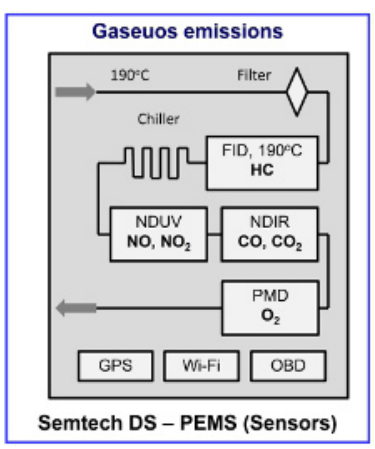

Figure 6. The measuring systems used for testing under real traffic conditions. a)

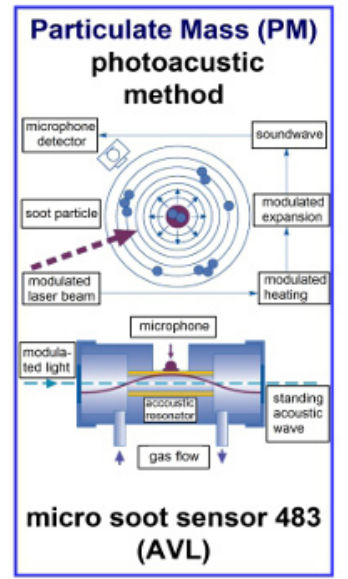

b)

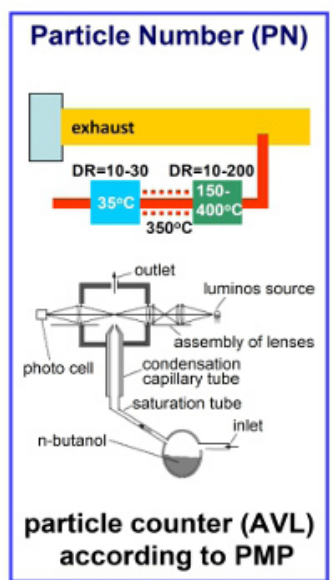

Figure 7. Measurement system used for testing particle emissions: a) analyser for measurement of the particle mass concentration - AVL MOVE (micro soot sensor + gravimetric), b) particle counter (AVL) for measurement of particle number.

\section{Results and analysis of road tests}

Values of emission correction for pollutants obtained in road tests were as follows:

For cars powered with Gasoline engines (Fig. 8):

- for those meeting the Euro 4 standard (vehicles with multi-point fuel injection and displacement from $0.7 \mathrm{~L}$ to $3.0 \mathrm{~L}$ were tested): the correction factor for on-road emission of carbon monoxide $C F_{\mathrm{CO}}$ was between 0.05 and 0.1 with a median value of 0.08 ; the conformity factor median value for hydrocarbons $C F_{\mathrm{THC}}$ was 0.04 and the conformity factor for nitrogen oxides $C F_{\mathrm{NOx}}$ was between 0.08 and 0.2 (with a median of 0.15 ). The conformity factor for particle mass did not exceed a value of 0.15 , with a median value of 0.07 (the $5 \mathrm{mg} / \mathrm{km}$ emission limit was adopted as an allowed value for particle mass emission - the same as for the Euro 5 standard);

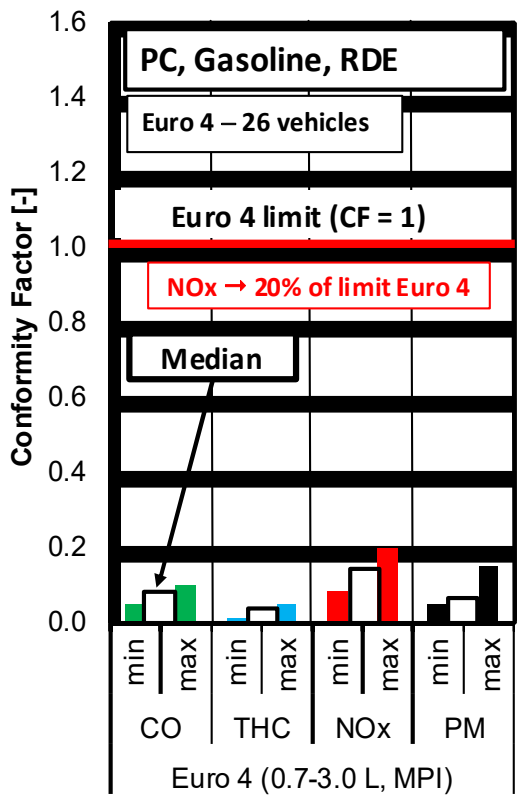

Figure 8. Values of passenger car emission conformity factors $(C F)$, for vehicles powered by gasoline engines meeting emission standards of Euro 4 (data acquired from 26 vehicles).

- for those meeting the Euro 5 standard (vehicles with direct injection and displacement from $0.7 \mathrm{~L}$ to $2.5 \mathrm{~L}$ were tested; Fig 9): the conformity factor of carbon monoxide $C F_{\mathrm{CO}}$ was between 0.03 and 0.08 with a median value of 0.06 ; the median value of the $C F_{\mathrm{THC}}$ was 0.05 (minimum and maximum values were 0.03 and 0.08 , respectively), conformity factor for nitrogen oxides $C F_{\mathrm{NOx}}$ were between 0.2 and 0.8 (with a median value of 0.41 ); the conformity factor for particle mass did not exceed 0.5 (with a median value of 0.15 ); for vehicles other than those fulfilling the Euro 5 standard the limit of $5 \mathrm{mg} / \mathrm{km}$ was applied;

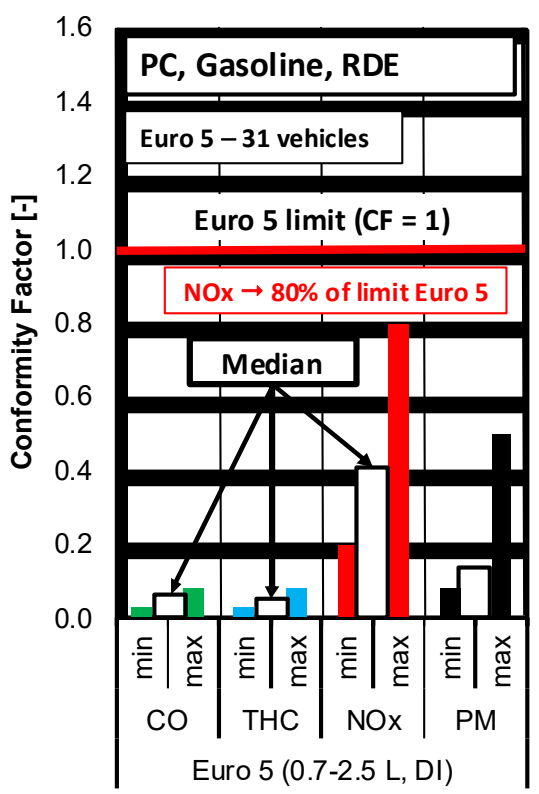

Figure 9. Values of passenger car emission conformity factors $(C F)$, for vehicles powered by gasoline engines meeting emission standards of Euro 5 (data acquired from 31 vehicles). 
- those meeting the Euro 6 standard (Fig. 10, vehicles with direct fuel injection and engine displacement from $1.0 \mathrm{~L}$ to $2.5 \mathrm{~L}$ were tested - without gasoline particulate filters): the median value of the conformity factor for on-road emission of carbon monoxide $C F_{\mathrm{CO}}$ was 0.09 (with extreme values of 0.02 and 0.11 ); the median value of the conformity factor of hydrocarbons $C F_{\mathrm{THC}}$ was 0.17 (with border values of 0.04 and 0.02 ); the conformity factor for nitrogen oxides $C F_{\mathrm{NO}}$ was between 0.12 and 0.7 (with a median value of 0.46 ); the conformity factor of particulate matter emission $C F_{\mathrm{PM}}$ did not exceed 0.6 (a median value of 0.42 ); the conformity factor of particle number behaved somewhat differently - the median value was 1.06 (with extreme values of 0.2 and 1.5); for vehicles powered with Euro 6c Gasoline engines the emission value for particle number was exceeded by more than $50 \%$ of the value of the limit (i.e. the highest observed value of $C F_{\mathrm{PN}}$ was 1.5 ).

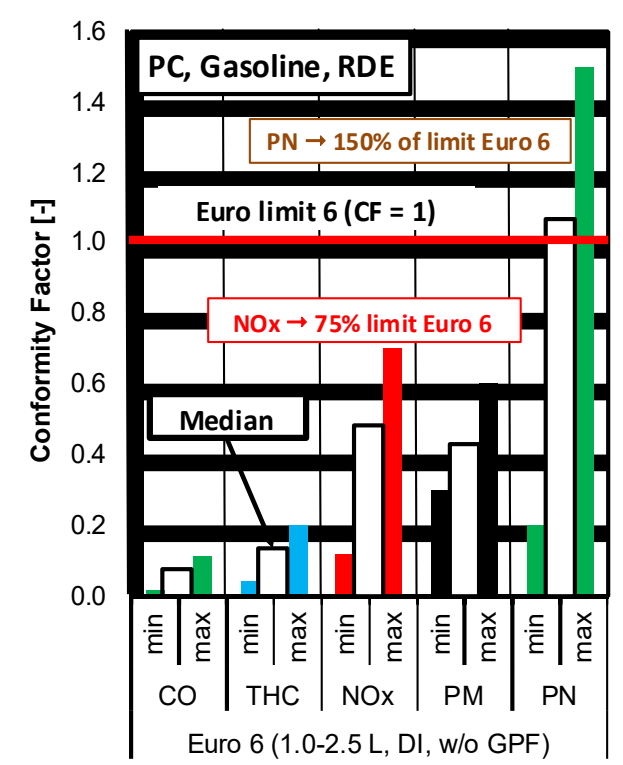

Figure 10. Values of passenger car emission conformity factors $(C F)$, for vehicles powered by gasoline engines meeting emission standards of Euro 6 (data acquired from 12 vehicles).

For cars powered by Diesel engines (a deviation from the legislation is used here - THC and $\mathrm{NO}_{\mathrm{x}}$ emissions results are reported separately here, although EU legislation specifies a limit in terms of $\mathrm{THC}+\mathrm{NO}_{\mathrm{x}}$ for vehicles with Diesel engines; the THC limit is equal to $\left.\left(\mathrm{THC}+\mathrm{NO}_{\mathrm{x}}\right)-\mathrm{NO}_{\mathrm{x}}\right)$ :

- those meeting the Euro 4 standard (vehicles with displacements between 1.3 L and 2.2 L w/o Diesel particulate filter, Fig. 11): the conformity factor for carbon monoxide $C F_{\mathrm{CO}}$ was between 0.0 and 0.05 with a median value of 0.04 ; the median value of hydrocarbon emission $C F_{\mathrm{THC}}$ was 0.4 ; the conformity factor for nitrogen oxides $C F_{\mathrm{NOx}}$ was between 0.8 and 1.4 (maximum exceed over the standard of $40 \%$ was observed and a median value of 1.0 was noted). The conformity factor for particulate matter emission did not exceed a value of 1.3 with a median value of 0.7 (so an excess of $30 \%$ was observed compared to the emissions standard);

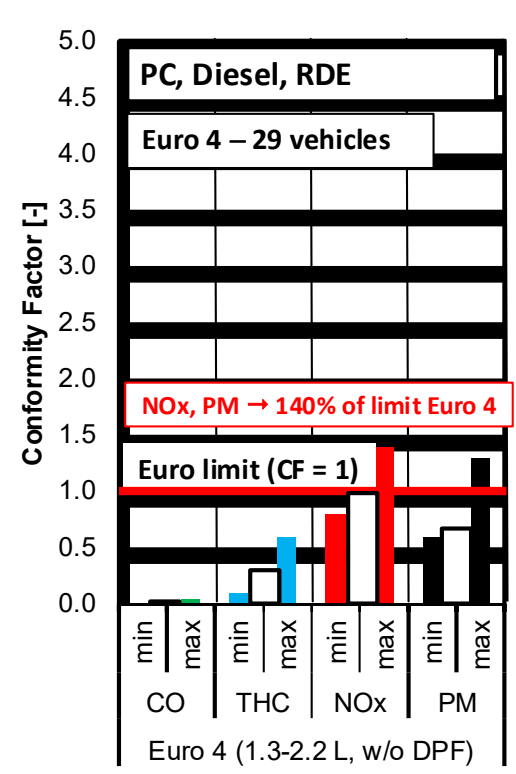

Figure 11. Values of passenger car emission conformity factors $(C F)$, for vehicles powered by Diesel engines meeting the Euro 4 emission standards (data acquired from a total of 29 vehicles).

- those meeting the Euro 5 standard (vehicles with displacements ranging from $1.3 \mathrm{~L}$ to $2.4 \mathrm{~L}$ with Diesel particle filter, Fig. 12); the conformity factor for on-road emission of carbon monoxide $C F_{\mathrm{CO}}$ was between 0.01 and 0.03 with a median value of 0.02 ; the median value of the conformity factor for hydrocarbons $C F_{\mathrm{THC}}$ was 0.5 (with minimum and maximum values of 0.3 and 0.7 ); the conformity factor for nitrogen oxides $C F_{\mathrm{NOx}}$ was between 1.4 and 3.7 (the median value was 3.2 - three times the amount allowed in the Euro 5 standard), the conformity factor for particle mass did not exceed a value of 0.2 (with a median value of 0.15 ); PN emissions were not measured for those vehicles. For this emission class, the greatest excess observed was for nitrogen oxides - exceeding three times the permitted value;

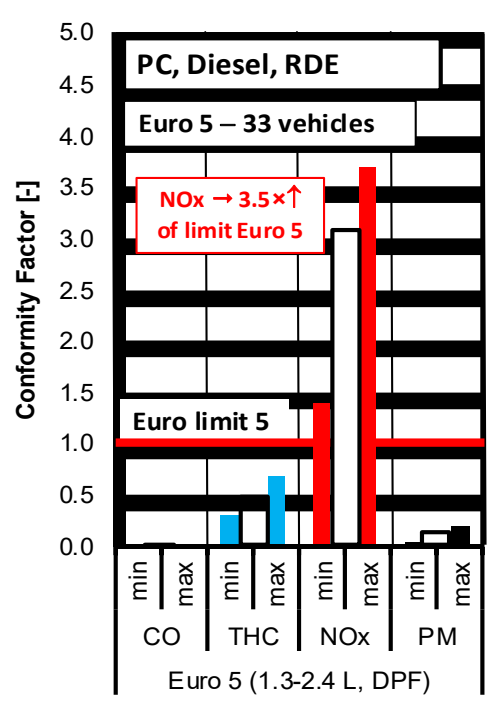

Figure 12. Values of passenger car emission conformity factors $(C F)$, for vehicles powered by Diesel engines meeting the Euro 5 emission standards (data acquired from a total of 33 vehicles). 
- those meeting the Euro 6 standard (vehicles with displacement ranging from $1.3 \mathrm{~L}$ to $3.0 \mathrm{~L}$ with Diesel particulate filter, Fig. 13): the median value for the on-road emission conformity factor of carbon monoxide $C F_{\text {CO }}$ was 0.2 (with extreme values of 0.02 and 0.3 ); the median value of hydrocarbon emission factor $C F_{\mathrm{THC}}$ was 0.5 (minimum and maximum values of 0.3 and 0.7 ); the conformity factor for emission of nitrogen oxides $C F_{\mathrm{NOx}}$ was between 1.1 and 4.8 (with the median value being 3.4 ); the conformity factor for particle mass $C F_{\mathrm{PM}}$ did not exceed a value of 0.3 (the median value being 0.26 ); the value for particle number followed a similar trend with a median value of 0.71 (with border values of 0.3 and 0.9); for Diesel engines in the Euro 6 emission class, high excess emissions of nitrogen oxides were observed (more than 3.5 times the limit - with a 4.8 maximum excess value).

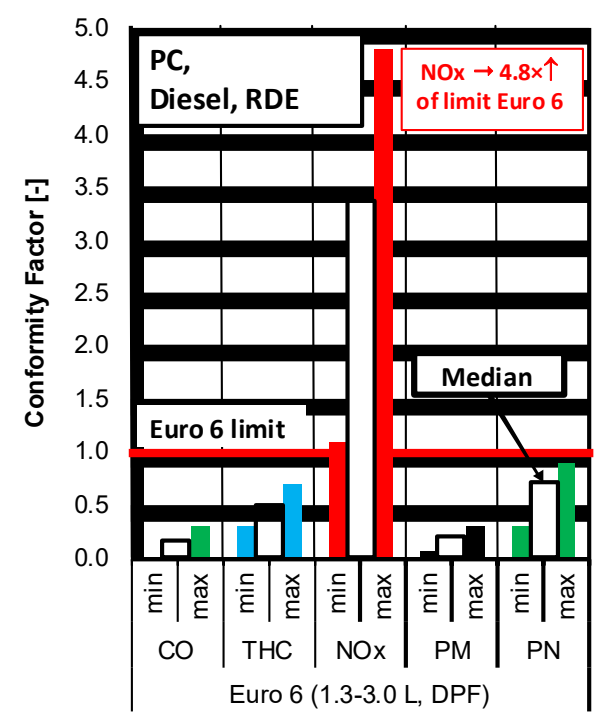

Figure 13. Values of passenger car emission conformity factors $(C F)$, for vehicles powered by Diesel engines meeting the Euro 6 emission standards (data acquired from a total of 18 vehicles).

\section{Conclusions}

The experimental work and associated numerical analyses presented in this paper allow the following conclusions to be drawn.

Conformity factors for gasoline engines in the Euro 4 and 5 emission classes in road tests (depending on vehicle weight and the level of the engine and aftertreatment technology applied) are $C F_{j}=0.8$ for all emission components. For gasoline direct injection vehicles meeting the Euro 6 standard, the conformity factor values obtained for particle number exceeded the values obtained over type approval test cycles. The average value of the conformity factor for emission of particle number in road tests was $C F_{\mathrm{PN}}=1.06$ (with a maximum value of 1.5 ).

The values of the conformity factor for vehicles powered by Diesel engines were found to be different: it has been shown that the values of the correction factors for emission of carbon monoxide and hydrocarbons are lower than 1 (i.e. the emissions limits are met), but for on-road emission of nitrogen oxides values between $C F_{\mathrm{NOx}}=0.7-4.8$ were observed (only extreme values are shown here). The same goes for particle mass and number (values of the conformity factor were as follows: $C F_{\mathrm{PM}}=0.2-1.3$ and $\left.C F_{\mathrm{PN}}=0.3-0.9\right)$.

In European future Portable Emission Measurement Systems will be necessary to measure exhaust emissions in real traffic conditions. The main issue of RDE is nitrogen oxides emissions but European Commission is also interested in particles measurement especially on gasoline direct injection. Wide variety of boundary conditions in RDE test must be considered. These influencing parameters have to be taken into account when evaluating RDE data and are addressed by route criteria, data evaluation tools and conformity factors. In 2016 the RDE Monitoring phase shall start for new vehicle types. Current RDE draft introduces the 'not-to exceed' regulatory concept which will be implemented starting in 2017. The ,not-toexceed" values are simply the Euro 6 limit multiplied by a conformity factor. Temporary conformity factor for nitrogen oxides emissions was suggested at the level of 2.1. Considering measurement uncertainty of PEMS the final conformity factor was suggested on the level of 1.0 plus a margin of 0.5 .

\section{References}

1. T. Bougher, I. Khalek, S. Trevitz, M. Akard, Verification of a gaseous portable emissions measurement system with a laboratory system using the Code of Federal Regulations Part 1065. SAE Paper Series 2010-01-1069 (2010)

2. M. Weiss, P. Bonnel, R. Hummel, U. Manfredi, R. Colombo, G. Lanappe, Analyzing On-road Emissions of Light-Duty Vehicles with Portable Emission Measurement Systems. Publications Office of the European Union, Technical Report EUR $24697 \mathrm{EN}$ (2013)

3. P. Bielaczyc, A. Szczotka, A. Swiatek, J. Woodburn, A comparison of ammonia emission factors from Light-Duty Vehicles operating on gasoline, liquefied petroleum gas and compressed natural gas. SAE Int. J. Fuels Lubr. 5, 2 (2012)

4. J. Merkisz, J. Pielecha, R. Jasiński, Real driving emissions testing of vehicles powered by compressed natural gas. SAE Paper Series 2015-01-2022 (2015).

5. J. Merkisz, J. Pielecha, P. Bielaczyc, J. Woodburn, Analysis of emission factors in RDE tests as well as in NEDC and WLTC chassis dynamometer tests. SAE Paper Series 2016-01-0980 (2016)

6. J. Merkisz, J. Pielecha, S. Radzimirski, New trends in emission control in the European Union (Springer Tracts on Transportation and Traffic, New York, 2014)

7. G. Fontaras, V. Franco, P. Dilara, G. Martini, U. Manfredi, Development and review of Euro 5 passenger car emission factors based on experimental results over various driving cycles. Science of the Total Environment 468-469 (2014) 
8. G. Kadijk, P. van Mensch, J. Spreen, Detailed investigations and real-world emission performance of Euro 6 Diesel passenger cars. TNO Report, R10702 (2015)

9. M. Weiss, P. Bonnel, R. Hummel, N. Steininger, A complementary emissions test for Light-Duty Vehicles: assessing the technical feasibility of candidate procedures (No. EUR 25572 EN). JRC Scientific and Policy Reports, European Commission 1, 56 (2013)

10. L. Yang, V. Franco, P. Mock, R. Kolke, S. Zhang, Y. $\mathrm{Wu}, \mathrm{J}$. German, Experimental assessment of NOx emissions from 73 Euro 6 Diesel passenger cars. Environmental Science \& Technology 49, 24 (2015)

11. C.L. Myung, S. Park, Exhaust nanoparticle emissions from internal combustion engines: a review. International Journal of Automotive Technology 13, 1 (2012)
12. Y. Chen, J. Borken-Kleefeld, Real-driving emissions from cars and light commercial vehicles - results from 13 years remote sensing at Zurich. Atmospheric Environment, 88 (2014)

13. V. Franco, F. Posada Sánchez, J. German, P. Mock, White paper: real-world exhaust emissions from modern diesel cars. Part 2: detailed results. The International Council on Clean Transportation (2014)

14. Automotive Industry, Report 2015, Polish Automotive Industry Association (2016)

15. European Vehicle Market Statistics Pocketbook 2013. International Council on Clean Transportation Europe (2014)

16. J. Merkisz, J. Pielecha, W. Gis, Gasoline and LPG vehicle emission factors in a road test. SAE Technical Paper Series 2009-01-0937 (2009) 